\title{
POR QUE AINDA É IMPORTANTE PENSAR COMO UM NÔMADE EM NOSSO TEMPO?
}

\author{
Hélio Rebello Cardoso Júnior*
}

\begin{abstract}
RESUMO
O presente artigo desenvolve o argumento de que existe um modo nômade de pensar em consonância com proposições formuladas a este respeito por Deleuze e Guattari. Procuraremos desenvolver tal argumento por meio da determinação de quatro eixos de reflexão, a saber, epistemológico, político, histórico e ontológico. Em conjunto, esses quatro eixos a serem caracterizados perfazem o que denominamos de pensamento nômade. Tal reflexão especifica-se no sentido de observar um processo de constituição de subjetividades dominante e regrados por uma "axiomática capitalista" em nosso tempo. Tal processo é entendido como um dispositivo nômade envolvendo, como subproduto, o que se denomina de narcisismo da diferença. Ora, se os modos de subjetivação dominantes regrados pela sociedade capitalista, em nosso tempo, são nômades, de que ainda valeria continuar pensando como um nômade, como queriam Deleuze e Guattari?
\end{abstract}

Palavras-chave: Deleuze. Guattari. Foucault. Nomadismo. Subjetividade.

\begin{abstract}
This article argues for the existence of a nomadic way of thinking, in accord with Deleuze and Guattari's proposals throughout their "nomadology". I will look forward to develop such an argument through of four points: the epistemological, the political, the historical and the ontological one. These four points, in set, describe what we call nomadic thought. Such reflection is defined in the observation of a dominant process that constitutes subjectivities ruled by a "capitalist axiomatic", in our time. Such process is understood as a nomadic device involving, as its main by-product, what is called of narcissism of the difference. However, if the dominant way of becoming subjects ruled by capitalist society, in our
\end{abstract}

\footnotetext{
* Doutor em Filosofia pela Universidade Estadual de Campinas (UNICAMP). Professor de Filosofia da Universidade Estadual Paulista (UNESP). Livre-docente em Filosofia pela Universidade Estadual Paulista (UNESP).E-mail: herebell@hotmail.com
} 
time, is nomadic, is it still worthwhile thinking as a nomad, as pursued Deleuze and Guattari?

Keywords: Deleuze. Guattari. Foucault. Nomads. Subjectivity.

O objetivo da presente reflexão é entender porque se torna necessário um pensamento nômade em nossa época. Como o campo argumentativo assim definido é demasiado para o espaço de que dispomos, especificaremos a temática do pensamento nômade, discutindo a maneira pela qual se pode pensar a constituição de subjetividades, hoje em dia, de modo nômade. A este respeito, tomaremos como apoio a obra de Deleuze e Guattari que, em seu famoso livro, Mil Platôs, desenvolvem um intenso capítulo acerca da "nomadologia" (DELEUZE; GUATTARI, 1980, p. 434-527).

São os seguintes os eixos da reflexão assim delimitada, a serem descritos na sequência:

a) eixo epistemológico relativo a um pensamento cujo modelo seja hidráulico, isto é, que se constitua em torno do fluido e não do stático;

b) eixo histórico a respeito das práticas de subjetivação, principalmente, quanto à mudança da "sociedade disciplinar" para uma "sociedade de controle";

c) eixo político acerca força de resistência em face de novas técnicas de controle das forças criativas do corpo e;

d) eixo ontológico em torno de um "novo nomadismo" e de um "narcisismo da diferença" promovido pela sociedade capitalista atual.

\section{Eixo epistemológico}

Deleuze e Guattari fornecem uma síntese de sua reflexão epistemológica em Mille Plateaux, quando são apontados dois tipos de cientificidade: a ciência maior e a ciência menor. Com essa correlação, apontam para a possibilidade de um conhecimento nômade (DELEUZE, 1980, p. 446-447).

Em primeiro lugar, a ciência maior e a ciência menor possuem modelos de cientificidade diversos: para a primeira vale uma "teoria dos sólidos" e já a ciência menor dispõe de uma "teoria dos fluidos". 
Em segundo lugar, os dois tipos de ciência contêm características relativas à temporalidade também diferenciadas. A ciência maior baseia-se em uma noção de tempo ligada à estabilidade espacial dos corpos, sendo a instabilidade tomada como um caso especial, um estado efêmero que será superado ao se restabelecer o equilíbrio originário. Já, para a ciência menor, o devir e a instabilidade são tomados como características de uma temporalidade líquida.

Por fim, sendo o modelo temporal de cada um diverso, altera-se, por conseguinte, o modelo espacial que preside cada caso de cientificidade. A ciência maior ocupa um espaço fechado onde as coisas lineares e sólidas são distribuídas por uma lei exterior ou transcendente ao sistema. Já, na ciência menor, o espaço é aberto, ele se confunde com a distribuição dos fluxos que o percorrem.

A correlação entre o modelo dos sólidos e o modelo dos fluidos proporcionaria um conhecimento nômade, desde que a ciência menor tivesse uma certa precedência sobre a ciência maior. Como assim?

A correlação entre ambos os tipos de cientificidade é possível, assevera Deleuze, desde que intervenha uma teoria das multiplicidades capaz de fazer comunicar as "intuições" da ciência menor à "estrutura teoremática" da ciência maior (DELEUZE, 1980, p. 604-605). Tal proposição se sustenta devido à cláusula ontológica segunda a qual a matéria ou os corpos possuem dois regimes de realidade.

Com efeito, a matéria possui dois regimes de multiplicidade: a multiplicidade não métrica, qualitativa e de fusão e a multiplicidade métrica, numérica e homogênea. Vejamos sucintamente o modo de coexistência entre esses regimes de multiplicidade, sob a ótica da interação entre ciência maior e ciência menor.

Deleuze enfatiza reiteradamente que não se trata da alternativa entre dois regimes de multiplicidade. Eles são coextensivos e imanentes, relativos à materialidade das coisas. Assim, a multiplicidade métrica é o regime das formas discretas dos corpos (extensões) e, por isso, de seu ponto de vista, os corpos são classificados segundo suas semelhanças sólidas (de gênero, de espécie, de estado, de natureza, de sistema). Já a multiplicidade não-métrica revela na matéria os devires ou fluxos que tendem a desfazer as formas e que, por isso, deixa perceber o caráter 
líquido ou acontecimental da matéria. A primeira, por isso, obedece a um esquema teoremático; enquanto a segunda, a um esquema intuitivo. Sendo assim, a cooperação entre ambas as ciências torna-se clara: a ciência maior passa a ser um sistema de tradução, não das atualizações da matéria entre si (multiplicidade métrica), mas das transmutações a que os acontecimentos submetem essas atualizações ou daquilo que as efetuações espaçotemporais acolhem nos acontecimentos (multiplicidade não-métrica).

Então, somos convidados, por meio dessas proposições a praticar um tipo de conhecimento nômade. Por exemplo, uma aula é um espaço sólido, pois há uma relação entre professor e aluna que sobressai. Trata-se de uma relação racional visando transmissão de conhecimento. Os pontos desse espaço sólido estão definidos: o professor em posição sobranceira, enquanto os ouvintes-alunos em posição de escuta e de atenção obediente. Essas posições parecem inamovíveis, sem sua hierarquia não haveria aula. Se alguns desses pontos ou posições se alteram, temos a impressão de que não se pode mais ter uma aula, por exemplo, se alguém conta uma piada ou canta uma ópera em sala de aula, se um gato ou cão entram no recinto inadvertidamente. Para manter-se unitária, apesar de todos os abalos que pode sofrer, seu equilíbrio deve ser forçado, temos de manter a aula por meio de em esforço. Essa é a aula enquanto multiplicidade atual.

Por sua vez, a aula enquanto multiplicidade virtual é um outro mundo. Outras coisas acontecem. Trata-se de um espaço fluido onde as posições não estão definidas, os alunos são micróbios e seus deslocamentos ou conversas na aula não dizem respeito a ela. Mesmo que todos estivessem atentos e concentrados, mesmo o professor, todos, somos atravessados por um formigamento ou agitação molecular que parece amolecer ou dissipar a aula sólida. Não há mais pontos de referência, uma aula se desmancha e começa a parecer-se com outra coisa. Não há uma lei clara dos pontos que constituem esse espaço fluido, o espaço se confunde com o próprio movimento. Não partimos de um ponto visando outro, não deixamos de ser menos ignorantes para nos tornarmos mais sabidos como numa aula atual. Tudo acontece pelo meio, a aula agora é apenas um lugar de passagem para fluxos de toda ordem. Em uma aula também há sono, delírio e catatonia, visões e audições que nada têm a ver com que o professor está falando. Os bichos entram e a aula recebe afetos animais. 
Para resumir, então, o problema de um conhecimento nômade é que uma aula atual ou sólida nada seria sem as variações que ela sofre devido à inquietude e ao formigamento da aula fluida ou virtual. Por isso deve-se pensar a matéria a partir de uma certa precedência da ciência menor sobre a ciência maior.

\section{Eixo histórico e eixo político}

Faremos a exposição dos eixos histórico e político do pensamento nômade de modo combinado, atentando para a ressonância e continuidade de seus termos, o que tornará mais ágil a presente exposição. Comecemos por exemplos que permitam ilustrar a manifestação histórica desses eixos, a fim de encaminharmos a caracterização de seus termos.

O conhecimento nômade permite pensarmos os modos pelos quais a subjetividade se constitui historicamente. Seguindo Foucault, podemos dizer que nossa subjetividade possui, desde o séc. XIX, um certo formato cujas operações se estabelecem dentro de uma "sociedade disciplinar". De acordo com Deleuze, a disciplina como modo de formar a subjetividade seria um modelo em crise, pois estaria em curso a constituição de uma "sociedade de controle" a qual implicaria novas subjetividades (DELEUZE, 1992, p. 219-226).

Vamos à caracterização das práticas de constituição de subjetividades em cada caso.

Toda sociedade impõe um controle social sobre o corpo, mas é exatamente esse controle que varia historicamente. Na sociedade disciplinar, o corpo é um objeto de análise e é fragmentado a fim de que a disciplina possa transformá-lo num "corpo útil", expressão de Foucault (FOUCAULT, 1999, p. 287). Mediante certas técnicas que se aplicam ao corpo, o ser humano é visado como um objeto que pode ser modelado. Foucault dá o exemplo dos exercícios militares, nos quais a coordenação dos movimentos dos soldados visa destituí-los de toda dimensão subjetiva, de modo que cada um deles possa estar ligado por operações formalizadas. Trata-se de uma organização do espaço - o espaço disciplinar - mas também do tempo, pois a ideia é que uma função disciplinar (operações formalizadas) molde os corpos em tempo contínuo dentro de cada espaço 
disciplinar. E, quando o indivíduo sai de um espaço para o outro (da família para a escola, por exemplo), ou seja, quando ele vai ser moldado segundo outra função (criar filho torna-se aprender como aluno), a operação exercida sobre o corpo no espaço anterior deve servir como preparo para a nova função.

Então, a sociedade disciplinar se organiza de acordo com a contiguidade de vários espaços disciplinares, onde funções, embora diferentes entre si quanto a seu objetivo, se interconectam no sentido de que obedecem ao mesmo diagrama ou organização. Desta forma, o ideal da sociedade disciplinar é maximizar o exercício da função em cada espaço para que as várias funções disciplinares se encadeiem sem lacunas. Além disso, a sociedade disciplinar precisa aumentar os espaços disciplinares, a fim de que o deslocamento dos indivíduos entre os vários espaços não interrompa a continuidade da modelação. Pode-se dizer que a disciplina controla os corpos para produzir subjetividades. Eis a produtividade do poder disciplinar: produção de individualidade por meio de modelagem dos corpos nos espaços disciplinares.

A grande lacuna da sociedade disciplinar era a questão dos espaços interdisciplinares. Procura-se coordenar todas as funções disciplinares, mas sempre restavam lacunas à disciplinarização. Por que?

Os saberes e os poderes de todos os tempos procuram domar os corpos, mas estes lhes escapam perfazendo uma história da resistência relativa à vida, pois "o ponto mais intenso das vidas, onde se concentra sua energia, fica exatamente ali onde elas se chocam com o poder, se debatem com ele, tentam utilizar suas forças e escapar de suas armadilhas" (FOUCAULT, 1977 apud DELEUZE, 1986, p. 101). O que acontece, então, é que, por mais disciplinadas que fossem, os corpos encontravam como ponto de fuga os espaços de intervalo entre os lugares de disciplinarização. Os espaços disciplinares não eram eficazes se não fossem pouco extensos. Em espaço aberto, a disciplina não alcançava as subjetividades. Esse era o ponto cego da sociedade disciplinar.

Ora, estamos, novamente, fazendo o uso de um conhecimento nômade. O espaço disciplinar sólido é o lugar de normatização das subjetividades e moldagem de individualidades, mas os entre espaços abertos eram o lugar de fuga ou de resistências nessas sociedades. Foucault 
descobrira esses pontos de resistência difusos, na maioria das vezes imperceptíveis para uma percepção disciplinar (FOUCAULT, 1985, p. 9192). Ele descobrira a potência nômade de nossos corpos.

Foucault (1985) ilustra fartamente a ideia de que há resistência à disciplinarização, pois a subjetividade diferencia-se das estratégias identitárias que buscam focá-la. Há, entre outros exemplos, a tarefa impossível da medicina da sexualidade em classificar o espaço ocupado pela homossexualidade. De fato, o tratamento das perversões de ordem sexual deflagrou um furor classificatório com o fito de registrar as mínimas diferenças entre comportamentos sexuais, expediente este relativo à "psiquiatrização do prazer perverso" (FOUCAULT, 1985, p. 53-55). O resultado dessa cruzada taxionômica é que os comportamentos sexuais perversos pareciam ter uma variedade infinita, de modo que os critérios para sua classificação nunca eram bastante. Ora, esse relativo fracasso por parte da medicina da sexualidade indica que toda disciplina deflagra uma resistência pela qual novos modos de comportamento são criados à revelia do dispositivo.

Em vista de relativo fracasso das disciplinas, a partir do século $\mathrm{XX}$, os dispositivos de captura das subjetividades começam a funcionar de acordo com uma nova dinâmica. As subjetividades passam a ser moldadas em espaço aberto. Elas não se reduzem mais à individualidade, ao centro de um "eu". Ao contrário, as subjetividades são formadas por feixes de fluxos que se combinam ou se afastam em um movimento acelerado. Os modos de moldagem dos sujeitos não mais se confinam aos espaços disciplinares, submetendo os indivíduos a uma vigilância generalizada essas novas práticas de compor subjetividades caracterizam o que Deleuze convencionou chamar de "sociedades de controle" (DELEUZE, 1992, p. 219-226).

Ao invés dos moldes de subjetividade baseados na identidade do indivíduo, teremos uma subjetividade em modulação contínua. Não precisamos mais estar em casa para nos sentirmos filhos ou na escola para aprendermos como aluno. Por um lado, somos filhos e alunos em qualquer parte, pois ser filho ou aluno é um fluxo que passa por nós. Por outro, temos uma margem de escolha, pois como a subjetividade é apenas o ponto de cruzamento de diversos fluxos, então, podemos deixar de ser filhos ou 
alunos quando ser um ou outro satura.

Então, vivemos quanto à nova sociedade de controle uma situação paradoxal.

Os lugares, que na época da disciplina constituíam-se enquanto espaço de fuga e de resistência, são agora o lugar do controle. Parece que não adiante ser um nômade com relação aos espaços disciplinares, visto que a própria sociedade capitalista criou um dispositivo nômade que captura a subjetividade em movimento.

\section{Eixo ontológico}

O problema do nomadismo como ação histórica ou política, no entanto, encara um desafio maior. Um desafio de ordem ontológica. É que, em nosso tempo, não basta uma vontade de contestação; não é suficiente ser um outsider que se mete nas brechas dos espaços disciplinares para encarnar um nômade. Os Estados constituídos conseguiram, historicamente falando, constituir um nomadismo que lhes é próprio por meio dos mecanismos de modulação contínua do controle.

Deleuze faz referência à vigência de um "novo nomadismo" que se efetivaria sobre uma "máquina de guerra mundial", independente dos aparelhos de Estado delimitados nacionalmente. Nesse caso, temos o espaço nômade reconstituído por uma máquina a serviço de uma "axiomática capitalista", a qual vigora quando todos os fluxos que percorrem uma sociedade são regrados por um fluxo tomado como "equivalente geral", como o mercado ou o capital, que ultrapassa as fronteiras nacionais, criando territórios flutuantes e deslizantes que retalham e alinhavam um novo mapa mundi. Sendo assim, o capitalismo é capaz de recriar o nomadismo como um de seus territórios-base, por sobre Estados e sociedades altamente sedentárias.

O problema do nomadismo, atualmente, apresenta-se de modo evidente quanto à constituição de subjetividades, uma vez que tal processo toma um caráter cada vez mais nômade, em consonância com a vigência de uma máquina capitalística que coopta fluxos psíquicos, controlando as linhas de fuga ou desviantes. Toda vez que um fluxo de subjetivação (processo formador de subjetividades) passa por nós e experimentamos 
com ele a liberdade de nos tornarmos outros, automaticamente, estamos em uma rede de controle do capital. Podemos, por exemplo, estar sufocados sendo filhos e/ou alunos, então, um pouco de afetividade virtual (internet) faz bem, é como ar puro, porém, a rede mundial, assim como a família e a escola são fluxos coordenados pelo capital. O bebê tem uma vida completamente individualizada devido à parafernália técnica e de consumo que se criou em torno da infância. $\mathrm{O}$ aluno tem de se preparar continuamente para o mundo do trabalho, mesmo, já trabalhador, ele é um aluno em tempo contínuo, na empresa. Na internet, se configuram e se desfazem, circunstancialmente, nichos de comportamento (música, batepapo, amizade, amor, sexo, voyeurismo pela webcam), todos perpassados por algum fluxo de capital.

Uma ilustração do alcance de tal acontecimento é descrita por Orlandi (2001). Este autor faz observar que os processos de formação de subjetividades, gradativamente, abandonam o modelo de estabilidade de uma identidade construída em torno do indivíduo como referencial para a formação de subjetividades. A identidade quase não é mais o ponto de unidade de uma subjetividade; ela possui uma constituição nômade. Todos os sensores do senso comum presentes na nova sociedade de controle, de modo cada vez mais intenso, indicam que não há mais necessidade de alguém prender-se a uma identidade e, se há uma crise sobre o que somos, já não dizem que nossa identidade está à espera em algum lugar recôndito que só nós mesmos podemos encontrar. Não temos mais de nos culpar pela falta que uma identidade faz. Cada subjetividade, hoje em dia, é um feixe de fluxos que constituem, na verdade, subjetividades portáteis ou dobráveis, de certa forma montáveis e desmontáveis. Configura-se um "neonarcisismo", alerta Orlandi, em que o perigoso embevecimento com a contemplação de si mesmo, praticada por Narciso no espelho das águas, tende a ser substituída por uma série de exposições ou flashes, cujo controle parece fugir ao sujeito.

O sujeito neonarcísico, com efeito, compõe-se por meio de uma potência de variação, por uma potência de diferenciação que não está de todo sob seu domínio. Como não controla o processo que constitui sua subjetividade, vige uma espécie de "aparelho" ao qual ele precisa recorrer. A função deste aparelho é a de mediar a relação do indivíduo com os 
fluxos de subjetividade que ora o integram, ora o deixam. Tal aparelho é um dispositivo de controle pelo qual o indivíduo é capturado sempre que necessita agenciar as exposições mais ou menos fragmentadas de seu eu. A perda da identidade não é tão sofrível para um sujeito. Ele procurará, inclusive, intensificar essa perda, a fim de contabilizar mais rapidamente montagens e desmontagens nas exposições do "aparelho de intermediação". Em suma, cria-se com esses procedimentos um narcisismo da diferença, pelo qual a linha de diferenciação dos processos de composição de subjetividades (subjetivação) acha-se capturada por um dispositivo que atinge o coração desses mesmos processos. De repente, potências estranhas passam a atravessar a relação do si consigo mesmo.

Numa sociedade marcada por um "novo" "nomadismo" que se afirma, deve-se supor que mecanismos de controle de toda ordem (políticos, prisionais, psíquicos, etc.) se aprimorem em capturar as linhas de diferenciação dos processos de constituição de subjetividades, esse nomadismo de si, por assim dizer. Não temos motivos para crer que a individualidade não estaria à mercê dessas potências que a atravessam e a compõem. Não há que ter ilusões o que toca à função de proteção que tais mecanismos de controle exercem, pois a proteção vai de par com o controle. A questão, então, é aproveitar estrategicamente a proteção oferecida e, ao mesmo tempo, manter linhas de fuga com relação a essas máquinas que capturam o nomadismo de si em espaço aberto.

Mas como será possível continuarmos nômades diante dos novos nômades que, afinal de contas, somos nós mesmos?

\section{Conclusão}

Naturalmente, não há uma solução explícita para essa questão. Mas é diante dela que se aplica toda a necessidade de um pensamento nômade, mesmo em um mundo nomádico como o nosso. De fato, o pensamento nômade destila uma espécie de prudência que nos favorece em nossos trajetos nômades contemporâneos.

Deleuze alertou para a capacidade de apresentar novos problemas para as situações dadas (DELEUZE, 1992, p. 158-159). Trata-se de uma guerrilha de si contra si mesmo, contra os fluxos de potências que nos 
atravessam, pois não existe um recesso indevassável do eu, ao abrigo de todo perigo. Os fluxos que formam nossa subjetividade e que são espalhados a esmo pela sociedade de controle podem ser colocados sob novas problematizações que escapam às simulações que estão em ressonância com o modo de subjetivação capitalístico e, portanto, do "aparelho de intermediação", como o definimos acima.

Um dos caminhos para a resistência nômade diz respeito ao uma certa prudência com relação à esquizofrenia. A esquizofrenia não está dentro de nós, mas fora. $\mathrm{O}$ mundo em que vivemos nos impele para comportamentos esquizóides, uma vez que o controle capitalístico é eficaz se promove a fragmentação da subjetividade em fluxos, estimulando uma diferenciação narcísica, como vimos. A esquizofrenia é o ar que respiramos. Há, portanto, um sintoma ou característica genérica desse processo.

Deleuze uma vez declarou que seu livro, O Anti-Édipo, escrito em coautoria com Guattari, teria sido mal compreendido (DELEUZE, 2003). As pessoas entenderam para resistirem ao capitalismo tinham de encontrar um nicho, supostamente, refratário às forças do capital. Para sermos verdadeiros contestadores, tínhamos de ser drogados, marginais, não irmos mais à escola, nos tornarmos andarilhos. Ora, Deleuze declara que a mensagem do livro não era absolutamente esta, posto que a grande lição a respeito de nós mesmos e do mundo em que vivíamos seria a de evitar nos tornarmos esquizofrênicos. Para isso o Anti-Édipo fora escrito.

A esquizofrenia possui uma grande potência de criação. $O$ esquizofrênico de hospital é sempre alguém em que um processo de criação falhou ou foi abortado por não interessar mais ao modo de produção de subjetividades vigente em nossa sociedade. Por isso, diz Deleuze a respeito da proposta que ele e Guattari apresentam em O Anti-Édipo: "nós colocamos um problema bem simples, semelhante ao de Borroughs a propósito da droga: será que é possível captar a potência da droga sem se drogar, sem se produzir como um farrapo drogado? É mesma coisa para a esquizofrenia" (DELEUZE, 1992, p. 35).

Quanto ao nosso tempo, este em que medram as diferenças narcísicas, teremos de exercitar uma certa prudência com relação a uma suposta conquista do nomadismo do qual todos participamos. É o modo pelo qual poderemos, com sorte, evitar a esquizofrenia para a qual é 
impelida nossa subjetividade. Qual o preceito de prudência com relação ao novo nomadismo, o qual faz de nós subjetividades equilibradas sobre fluxos esquizóides?

Quando vivemos nos espaços sólidos e sedentários da identidade, tememos todo o tempo perder a segurança, a grande organização que nos sustenta, as árvores onde nos penduramos, nós desejamos tudo isso por isso temos medo. "Nós fugimos da fuga, nós endurecemos". É o "medo" (DELEUZE; GUATTARI, 1980, p. 277). Esse é o primeiro perigo de se experimentar o nomadismo, isto é, o endurecimento do qual não nasce nenhum nômade.

Já, quando somos nômades de nós mesmos e caminhamos pelos espaços fluidos da diferença, ganhamos a micropercepção de que as grandes organizações têm seus poros, seus buracos, pelos quais podemos escapar. É a "clareza". Antes, víamos figuras de contornos bem definidos, mas a clareza faz o compacto diluir-se, agora as "coisas se rodeiam de franjas incertas, os maciços são escavados por movimentos migratórios, cavalgadas, fluxos que não se pode conter, nevoeiros. As coisas ganham a clareza da visão que se tem ao microscópio. Acreditamos ter enfim compreendido tudo e começamos a tirar conclusões. Somos novos cavaleiros e temos uma missão. Vencemos o medo, abandonados as margens da segurança, mas entramos no sistema das pequenas inseguranças" (DELEUZE; GUATTARI, 1980, p. 278). Cada um pode encontrar então seu buraco, se meter nele e de lá começar a arenga sobre as benesses de sua clareza. A clareza da diferença narcísica é um perigo, o perigo de ser nômade!

Essa foi a lição que Deleuze e Guattari tiraram de um livro, A erva do diabo, de Carlos Castañeda, considerado uma espécie de apologia das drogas (DELEUZE; GUATTARI, 1980, p. 277-279). Eles perceberam, no entanto, que este livro também não fora escrito pelas razões que julgamos evidentes, assim como $O$ Anti-Édipo.

\section{Referências}

DELEUZE, Gilles; GUATTARI, Félix. Mille Plateaux. Paris: Minuit, 1980. 
. Foucault. Paris: Minuit, 1986.

. Conversações. Rio de Janeiro: Ed. 34, 1992.

. O abecedário de Gilles Deleuze. Entrevista concedida a Claire Parnet. Vídeo. Transcrito e traduzido por Tomás Tadeu da Silva. Disponível em: <www.ufrgs.br/faced/tomaz>. Acessado em: 12 fev. de 2003.

FOUCAULT, Michel. História da sexualidade vol. I (a vontade de saber). 7. ed. Rio de Janeiro: Graal, 1985.

. Em defesa da Sociedade - Curso no Collège de France (19751976). São Paulo: Martins Fontes, 1999.

ORLANDI, Luiz B. L. Marginando a leitura deleuzeana do trágico em Nietzsche. Texto não publicado, gentilmente cedido pelo autor, 2001.

Data de registro: $17 / 02 / 2011$

Data de aceite: 18/05/2011 
